\title{
ATRIBUTOS RACIAIS NO FUNCIONAMENTO DO SISTEMA DE JUSTIÇA CRIMINAL PAULISTA
}

\author{
Renato SÉrgio de Lima
}

\begin{abstract}
Resumo: Este artigo avalia o papel de atributos raciais e de gênero no funcionamento do Sistema de Justiça Criminal de São Paulo. Mediante análises longitudinais, ou seja, análises que observam a trajetória dos indivíduos pelo interior do Sistema de Justiça Criminal (no caso, do inquérito policial até a execução da pena dos condenados pelo crime de roubo), pôde-se constatar o tratamento diferenciado a mulheres e homens, a negros e brancos.

Palavras-chave: gênero; raça; discriminação; sistema de justiça criminal.

Abstract: This article assesses the influence of race and gender in the functioning of the São Paulo State criminal justice system. Through the use of longitudinal analysis, that is, analysis that tracks individuals as they make their way through the criminal justice system (in this case, from indictment to the serving of the sentence for robbery), one may observe the different treatments accorded to women and men, blacks and whites. Key words: gender; race; discrimination; criminal justice system.
\end{abstract}

$\mathrm{A}$ proposta deste artigo é explorar o funcionamento das instituições do Sistema de Justiça Criminal (polícias Civil e Militar, Ministério Público, Poder Judiciário e Sistema Carcerário) e suas interações no processo de transformação democrática da sociedade brasileira, à luz das estatísticas sobre raça e gênero. Há a tentativa de se compreender a forma como as estatísticas sobre justiça criminal e segurança pública (categorias e classificações) são produzidas e incorporadas no funcionamento do Sistema de Justiça Criminal Brasileiro, em especial o de São Paulo. A preocupação central é investigar como informações e estatísticas dessa área podem traduzir uma série de processos sociais e, por conseguinte, podem constituir importante ferramenta analítica para os cientistas sociais envolvidos com o tema, na medida em que, como destaca Hacking (1991), as estatísticas não são desprovidas de ideologia, e retroalimentam o funcionamento e os interesses da burocracia de Estado - que, envolvida na produção das estatísticas, é uma das mais anônimas estruturas de Estado, e também a que determina não somente regras administrativas, mas classificações e critérios de seleção de prioridades de governo. O problema, portanto, seriam os parâmetros e os objetivos por detrás das classificações que, no limite, traduziriam a gramática e a linguagem do poder.

\section{CLASSIFICAÇÕES RACIAIS}

Depreende-se, portanto, que pensar nas classificações de indivíduos envolvidos com fatos de natureza criminal, e que foram objeto de atenção das agências públicas que compõem o Sistema de Justiça Criminal do país, implica pensar na possibilidade de existência de ideologias que movem tal Sistema. Um dos casos mais paradigmáticos é, exatamente, o que envolve a questão racial, em que a categoria "cor da pele" é aquela utilizada pela Polícia Civil, porta de entrada oficial dos indivíduos no Sistema de Justiça, para caracterizar os indivíduos vítimas ou autores de crimes. Inclusive, vale destacar que o critério de classificação é o da atribuição da cor pelo escrivão de Polícia, funcionário responsável pelo registro da ocorrência policial. $^{1}$

No entanto, o recorte cor sugere que alguém só pode ter cor e ser classificado por ela se existir uma ideologia 
na qual a cor das pessoas tem algum significado, ou seja, no interior de ideologias raciais. Da mesma forma, qualquer análise sobre questões raciais no Brasil deve começar por notar que o racismo no Brasil é um tabu. Os brasileiros se imaginam numa democracia racial e a propagam como motivo de orgulho nacional. Entretanto, quando se analisa a distribuição da população brasileira segundo o atributo cor, diferentes clivagens demonstram o quanto a imagem anti-racista não corresponde à realidade (Guimarães, 1995). Os negros estão entre os indivíduos com piores indicadores de renda, emprego, escolarização, entre outros e têm um tratamento penal mais severo para atos iguais aos cometidos por brancos.

Entre os argumentos utilizados para explicar tal fenômeno, há um, incorporado ao Movimento Negro e politicamente conveniente a ele, ${ }^{2}$ que merece destaque: numa sociedade em que, historicamente, o comportamento daqueles que vivem na pobreza é criminalizado - e os negros são, demograficamente, mais numerosos entre os pobres -, eles acabam por ser duplamente discriminados. Afinal, imagens sociais sobre crimes e criminosos associam atributos raciais e pobreza ao maior cometimento de crimes violentos, mesmo não existindo estudos que comprovem esta associação. Assim, os negros não são discriminados apenas pela cor, mas também pela origem social e, por conseguinte, a exclusão social é reforçada pelo preconceito e pela estigmatização. Nesse processo, sendo os negros vistos como indivíduos "perturbadores da ordem social", são eleitos alvos preferenciais das agências de controle social.

Essa concepção do negro como indivíduo perigoso e merecedor da atenção policial não é recente e, muito provavelmente, tem entre suas raízes explicativas, para além da questão socioeconômica, a compreensão dos negros como inferiores biológica e culturalmente aos brancos. Essa tese foi mais forte no final do século XIX e início do século XX. A afirmação de Oliveira Vianna, ao comentar as diferenças que localiza no interior da raça negra, é categórica e resume bem tal concepção. Segundo ele, “(...) os seus representantes [negros] não possuem todos a mesma unidade morphologica, nem a mesma mentalidade; ao contrário, variam mais ou menos sensivelmente num e noutro sentido, apresentando-se, às vezes, como nas duas raças inferiores, a negra e a vermelha, typos de tão acertada diversidade somatica e psychologica, que dir-se-iam provindos de raças inteiramente distinctas e inconfundiveis" (Oliveira Vianna, 1920: 313, grifo meu).
Ainda segundo Oliveira Vianna, a inferioridade negra é justificada com um argumento que hoje é visto como criminoso e que soa anacrônico e mesmo inaceitável. Para o autor, "não só a potencialidade eugenistica do Homo Afer é reduzida em si mesmo, como, posta em funcção de civilização organizada pelo homem da raça branca, ainda mais reduzida se torna. $\mathrm{O}$ negro puro nunca poderá, com effeito, assimilar completamente a cultura aryana, mesmo os seus exemplares mais elevados: a sua capacidade de civilização, a sua civilizabilidade, não vae além da imitação, mais ou menos perfeita, dos habitos e costumes do homem branco. Entre a mentalidade deste e a do homem africano puro há uma differença de estructura, substancial e irreductivel, que nenhuma pressão social ou cultural, por mais prolongada que seja, será capaz de vencer e eliminar (...)" (Oliveira Vianna, 1920: 328).

Dessa forma, o perigo seria resultado de uma múltipla combinação de fatores, onde "os typos ethnicos (...) não apresentam a mesma unidade de caracteres morphologicos, nem a mesma identidade de temperamento e mentalidade (...)" (Oliveira Vianna, 1920: 321). É possível pensar, a título de hipótese, que em um ambiente de então recente abolição da escravidão, essa concepção implicaria a justificativa moral para estruturar as agências de controle social na defesa dos interesses até então constituídos e a precaução contra eventuais ações "incivilizadas" das raças "inferiores".

Um exemplo da importância dessa discussão é a criação da Guarda Nacional, no século XIX, que teve papel fundamental na incorporação patrimonialista na administração pública brasileira, em especial nas instituições de Justiça (Uricoechea, 1980:14-16). No funcionamento da Guarda Nacional, um corpo profissional ficava responsável por policiar a capital e as principais cidades. Nas demais cidades e regiões do país, milícias voluntárias e mantidas pelos donos da terra locais ficavam responsáveis por controlar a população. Tais milícias tinham poder de polícia, mas funcionavam segundo os interesses de seus patrocinadores. Nesse processo, uma brecha formal estava criada, e a percepção da existência de critérios sobre quem e onde seria objeto da Justiça Pública implicava o reconhecimento de indivíduos "superiores" ou "inferiores".

O funcionamento da Justiça tinha sido pensado apenas para parcela da população, e nem a incorporação de todos os habitantes num regime jurídico único e a retomada do poder exclusivo de polícia pelo Estado, frutos dos debates republicano e abolicionista, não conseguiram alterar o quadro de princípios que organizava o modelo buro- 
crático do Sistema de Justiça. Mesmo a criação dos Juizados Especiais Cíveis e Criminais, nos anos 90, poderia, no limite, ser vista como um mecanismo de manutenção de dois tipos de justiça, dirigidos a dois tipos de indivíduos formalmente distintos.

Em reforço a esta tese, e saindo da esfera penal, o Código Civil Brasileiro, vigente até 10 de janeiro de 2003, foi elaborado no final dos anos 10 do século XX, e embutia valores sobre formas de organização social. Questões sobre casamento, pátrio poder, contratos e outros assuntos fundamentavam-se no pressuposto de que determinados segmentos da população deveriam ser "tutelados" seja pelo Estado seja pelo chefe de família, cujo símbolo é, exatamente, o homem maior e branco. Nessa chave, a imagem do Estado como "pai repressor" teria o suporte na visão de como deveria ser a educação e a transmissão de valores da sociedade. Assim, mulheres, crianças e adolescentes, indivíduos com problemas físicos e/ou mentais, bem como toda sorte de indivíduos que poderiam merecer a atenção especial do Estado, seriam alvo das agências de controle social. O funcionamento desigual do Sistema de Justiça tem na permanência do modelo burocrático do início do século XX e na visão da necessidade da "tutela" componentes fundamentais para a sua explicação e para a reificação do exercício não equânime do poder.

Os esforços para a constituição de um Movimento Negro politicamente capaz de interagir com a sociedade e de construir uma identidade negra não foram suficientes para transformar os fundamentos que dividiam brancos e não-brancos, homens e mulheres, em indivíduos portadores de direitos de cidadania plena. Em outras palavras, os dados a seguir, sobre o tratamento mais severo dispensado pelo Sistema de Justiça Criminal aos negros indicariam a soma de concepções racistas, aspectos socioeconômicos e demográficos e, ao mesmo tempo, de pressupostos morais e técnico-processuais que não foram objeto da transformação democrática desde os anos 80 do século passado.

Nesta direção, uma pesquisa que serviu de base para a redação de dissertação de mestrado, recentemente publicada, preocupou-se em analisar as vítimas e os autores identificados de crimes de homicídios cometidos na cidade de São Paulo, em 1995, segundo variáveis biográficosociais (Lima, 2002). Foram coletados dados sobre idade, sexo, escolaridade, naturalidade, profissão e, principalmente, para os objetivos desse trabalho, "cor da pele" das vítimas e dos autores identificados pela Polícia. Segundo a pesquisa, os dados sobre cor das vítimas e dos agressores de homicídios de autoria conhecida revelaram, àquela época, que os brancos, à primeira vista, estavam mais representados entre as vítimas $(61,2 \%)$ do que os negros (35,5\%). Entretanto, segundo informações extraídas dos Censos Demográficos do IBGE$^{3}$ (1980 e 1991), os negros, proporcionalmente à composição racial da população paulistana, estão mais representados entre as vítimas deste tipo de homicídio. Segundo projeções do IBGE para 1980, $72,1 \%$ da população residente do Município de São Paulo era composta por brancos, ao passo que os negros (pretos e pardos) totalizavam 24,6\%. Assim, pôde-se inferir, na pesquisa, que os negros têm um potencial de vitimização $44,3 \%$ superior à sua participação na composição racial da população paulistana. Entre os casos de homicídios de autoria desconhecida, observa-se que os brancos foram vítimas em $48,3 \%$ dos crimes e os negros em $41 \%$. Seguindo o mesmo raciocínio adotado para os homicídios de autoria conhecida, o potencial de vitimização de negros neste tipo de homicídio é $66,7 \%$ superior à sua participação na composição racial da população.

Nos dois tipos de homicídios analisados, observou-se que os negros, em relação à sua participação da composição racial da população do Município de São Paulo, estão muito mais representados tanto entre as vítimas como entre os autores destes crimes. Este fenômeno remete, contudo, à análise sobre os critérios adotados pelos agentes policiais para classificar um determinado indiciado por sua cor. Em outras palavras, o fato de os negros estarem mais representados - proporcionalmente à sua participação na população -, tanto entre as vítimas como entre os autores dos homicídios cometidos no Município de São Paulo, não significa que exista um padrão racial que possa explicá-los. A justificativa para este fenômeno estaria na distribuição espacial dos homicídios, que se concentram na periferia da capital, exatamente onde a parcela pobre e negra da população reside. O homicídio insere-se na lógica do espaço urbano de São Paulo e nas condições de vida que ele oferece (Lima, 2002).

Uma outra pesquisa produzida pela Fundação Seade (2000), sob encomenda da Secretaria de Administração Penitenciária de São Paulo, comparou as populações do Estado de São Paulo e dos estabelecimentos penitenciários paulistas, e indicou uma série de questões importantes, complementares às citadas anteriormente. Em primeiro lugar, conforme a Tabela 1, nota-se que os negros estão muito mais representantes na população carcerária do que na população em geral. Por certo, os brancos são numericamente superiores aos negros nas prisões paulistas, mas, 
proporcionalmente, estes últimos parecem ser mais punidos com pena de prisão do que os brancos. Pelos dados disponíveis, ${ }^{4}$ nota-se que enquanto os negros representavam cerca de $26 \%$ da população paulista, em 1999, eles totalizavam cerca de $44 \%$ da população carcerária em São Paulo.

TABELA 1

Distribuição da População Paulista e da População Carcerária, segundo Cor da Pele Estado de São Paulo - 1999

Em porcentagem

\begin{tabular}{lcc}
\hline Cor da Pele & População (PNAD) & População Presa \\
\hline Branca & 72,70 & 55,59 \\
Negra & 25,50 & 43,77 \\
Amarela/Indigena & 1,80 & 0,45 \\
Não Informado & 0,00 & 0,18 \\
\hline
\end{tabular}

Fonte: IBGE. Pesquisa Nacional por Amostra de Domicilios - PNAD; Tribunal de Justiça do Estado de São Paulo; Secretaria da Administração Penitenciária; Secretaria de Segurança Pública do Estado de São Paulo; Prodesp; Fundação Seade.

O Gráfico 1 avalia o percentual de mulheres e homens brancos e negros que foram indiciado(a)s (acusado(a)s formalmente pela prática de um crime, processado(a)s e que tiveram sentenças finais de prisão nos crimes de roubos consumados (artigo 157, do Código Penal). Nele, podem-se observar as intensidades das curvas e das trajetórias dos indivíduos, nas quais os homens brancos têm diminuída sua probabilidade de serem condenados e cumprirem, efetivamente, penas de prisão e, em sentido contrário, as mulheres negras são, proporcionalmente, muito mais punidas com prisão do que as demais mulheres e, mesmo, do que os homens negros.

Tais resultados reforçam aqueles identificados por Sérgio Adorno $(1994 ; 1995)$ e dão ainda mais dramaticidade ao quadro de funcionamento da Justiça Criminal Paulista, na medida em que cobrem o universo completo de indivíduos envolvidos com crimes de roubos. No funcionamento do Sistema de Justiça Criminal, não é possível compreender a distribuição desigual de sentenças condenatórias apenas afirmando a existência de racismo. Alguns estudos avançaram muito nessa compreensão, como os de Sérgio Adorno, acima citado, que observou que "a arbitrariedade dos procedimentos inquisitoriais pesa com maior rigor sobre réus negros do que sobre réus brancos. No mesmo sentido, réus negros tendem a enfrentar maiores obstáculos no acesso aos direitos" (Adorno, 1995: 53). Por trás deste processo, o funcionamento desigual do Sistema de Justiça seria resultado, sobretudo, de clivagens de classe na operação e no acesso à justiça.

No entanto, existem outros autores que defendem que a categoria "raça" não pode ser esvaziada pela categoria "classe", e que os estudos que fazem este tipo de associação seriam tributários de uma tradição sociológica que relaciona funcionamento e estrutura de classes da sociedade, e que nem mesmo essa associação entre raça e classe consegue dar conta de explicar o tratamento diferenciado do Sistema de Justiça para negros e brancos em toda a sua complexidade.

Segundo Guimarães (2002:47), ao associar classe e raça ficamos presos a duas armadilhas sociológicas. De acordo com o autor, "primeiro, o conceito de classes não é concebido como podendo referir-se a uma certa identidade social ou a um grupo relativamente estável, cujas fronteiras sejam marcadas por formas diversas de descriminação, baseadas em atributos como a cor (...). Segundo, o conceito de 'raças' é descartado como imprestável, não podendo ser analiticamente recuperado para pensar as normas que orientam a ação social concreta, ainda que as discriminações a que estejam sujeitos os negros sejam, de fato, orientadas por crenças raciais". Nes-

\section{GRÁFICO 1}

Trajetória dos Indivíduos Envolvidos em Roubos, segundo Raça e Gênero Estado de São Paulo - 1999/00

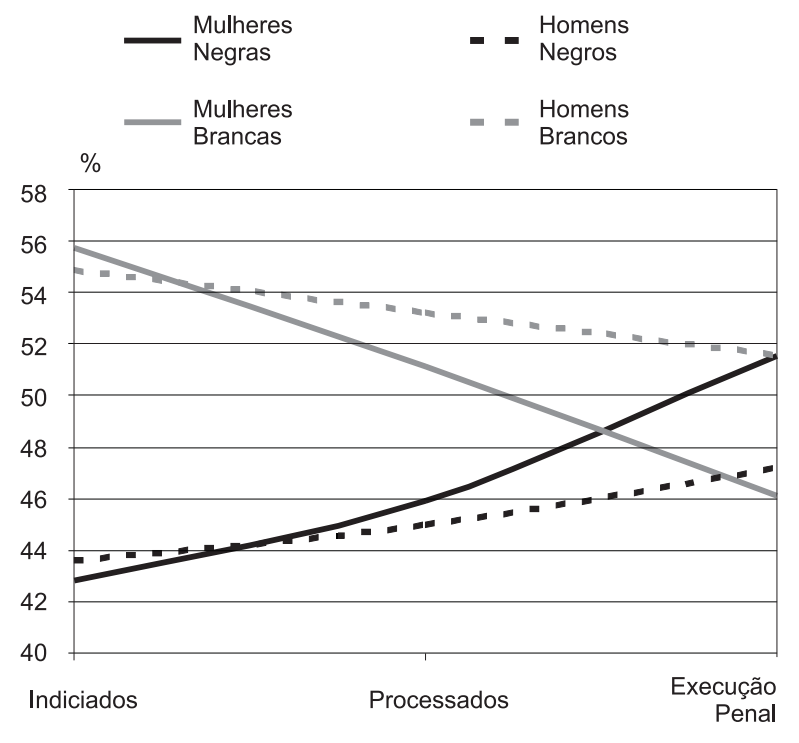

Fonte: Tribunal de Justiça do Estado de São Paulo; Secretaria da Administração Penitenciária; Secretaria de Segurança Pública do Estado de São Paulo; Prodesp; Fundação Seade. Nota: Dados preliminares. 
sa perspectiva, portanto, a categoria "raça" não pode ser descartada, mesmo que na prática ela não tenha outro significado que não o político, pois pesquisas recentes desmontaram de vez a possibilidade de se pensar, no Brasil, "raça" como resultado de atributos biológicos (Folha de S.Paulo, 17/12/2002: A16).

Enfim, a partir do acima exposto pode-se explicitar/ reforçar que o Sistema de Justiça Criminal Brasileiro é pautado por uma lógica que permite, no limite, a invisibilidade de questões raciais, de gênero ou geracionais no processamento de fatos de natureza criminal e, por conseguinte, permite a reificação de desigualdades, diferenças e discriminações na população do país, não incorporando as transformações democráticas da sociedade brasileira observadas no campo político. Segundo esta lógica, a desigualdade na forma de tratamento dispensado pelo Sistema de Justiça poderia ser explicada por duas clivagens demográficas principais: gênero e raça.

Por meio delas, o aparato técnico-processual montado para garantir a igualdade na distribuição de justiça estaria, na realidade, reproduzindo relações não equânimes de poder, e seria uma indicação de que o processo de transformação democrática da sociedade brasileira ainda está inconcluso. No caso específico do atributo racial, a existência de ideologias raciais permite montar um arcabouço institucional capaz de processar os conflitos de natureza criminal da sociedade brasileira e, ao mesmo tempo, capaz de garantir a permanência de lógicas de poder historicamente construídas como desiguais e destinadas a dispensar tratamento diferenciados para os vários segmentos demográficos.

Por certo, todo o processo de construção da identidade negra observado ao longo do século XX contribuiu para fazer avançar o debate sobre o funcionamento desigual do Sistema de Justiça. Contudo, pelos dados apresentados, ainda é necessário aumentar a compreensão deste fenômeno e debater aspectos poucos explorados pelos cientistas sociais envolvidos com a temática da Justiça Criminal e da Segurança Pública.

No momento, não existem condições para fazer associações e/ou afirmações definitivas, mas sim para incluir tópicos de debate. Pensar no modelo burocrático e no pressuposto da tutela ajuda a aumentar a compreensão do fenômeno, mas não equaciona de vez a questão, pois a literatura norte-americana e européia, por exemplo, indica que o tratamento diferenciado do Sistema de Justiça Criminal é uma realidade não apenas do Brasil, mas também perpassa a história dos Estados Unidos e dos países da Europa. Dessa forma, há de se destacar que alterações nesse quadro passam pela incorporação marginal de transformações, em especial aquelas pautadas pelos movimentos sociais. Sobretudo após a Constituição de 1988, foi na esfera dos direitos difusos - da Criança e do Adolescente, do Meio Ambiente e do Consumidor - que a mudança de paradigma no exercício da distribuição de justiça pôde ser exercida e notada. Sem dúvida, tal mudança provocou um "choque de transparência" e está a exigir uma nova postura do Estado na forma de relacionar-se com a sociedade e, mais, na forma como ele está organizado para mediar e resolver conflitos.

\section{NOTAS}

1. Para efeito de análise, será mantida a denominação do aparelho policial por todo o texto deste trabalho.

2. Segundo Guimarães (2002), o Movimento Negro reivindica a prerrogativa da maioria discriminada, ou seja, além dos classificados como "pretos" e que estariam diretamente associados à raça negra, vê naqueles indivíduos identificados como pobres e cuja "cor" situa-se na categoria "pardos", na qual se encaixaria a maioria da população brasileira, as marcas de identidade que permitiriam o discurso da raça negra como discurso político da maioria e, portanto, com maior grau de "legitimidade".

3. Informações para o Município de São Paulo não puderam ser obtidas no Censo de 1991, pois os dados disponíveis estavam agregados para o total do Estado. Para o Estado de São Paulo, os brancos representavam, naquele ano, $72,5 \%$ da população e os negros, $25,4 \%$.

4. Cabe destacar, como ressalva metodológica, que, para a distribuição da situação de prisão segundo "cor", utiliza-se a população total de presos do Estado de São Paulo e não somente uma amostra. No caso da distribuição da população, trabalha-se com a PNAD (Pesquisa Nacional por Amostra de Domicílios) do IBGE, que, apesar de ser uma amostra, já é uma estimativa da população geral. Com uma "amostra" tão grande, há a tendência de hiper-sensibilidade dos testes estatísti$\cos$, sendo que pequenas diferenças serão significativas não por diferenças reais, mas em virtude da estrutura do teste. Assim, testes estatísticos de natureza probabilística não são indicados para amostras grandes. Portanto, as análises dos dados aqui apresentadas partem de inferências de natureza qualitativa. Também é necessário indicar que as análises feitas têm por base as informações disponíveis no Sistema Integrado de Informações Criminais e, por conseguinte, são suscetíveis à existência de vieses na coleta e produção das informações. Sabese, pela literatura existente, que a qualidade dos dados varia de acordo com a fonte que o coleta. Dados sobre, por exemplo, cor da pele são coletadas pela Polícia no momento do indiciamento do indivíduo acusado de um crime. No entanto, os critérios de classificação de um indivíduo como de uma cor ou de outra não são uniformes, e estão sujeitos a avaliações subjetivas do agente policial responsável por tal procedimento. Significa dizer que as análises dizem respeito tão somente aos dados existentes no Sistema Integrado gerenciado pela Prodesp Empresa de Processamento de Dados do Estado de São Paulo. 


\section{REFERÊNCIAS BIBLIOGRÁFICAS}

ADORNO, S. Discriminação racial e justiça criminal em São Paulo. Novos Estudos, São Paulo, Cebrap, n.43, p.45-63, nov. 1995.

. Crime, justiça penal e desigualdade jurídica. Revista USP. São Paulo, n. 21, p.132-151, mar./abr. 1994.

FOUCAULT, M. As palavras e as coisas. São Paulo: Martins Fontes, 2002 .

. Em defesa da sociedade. São Paulo: Martins Fontes, 2000.

. Microfísica do poder. 10.ed. Rio de Janeiro: Edições Graal, 1992.

. Vigiar e punir: história da violência nas prisões. 9.ed. Petrópolis: Vozes, 1991.

FUNDAÇÃO SEADE. Estudo piloto da trajetória dos individuos presos pelo interior do sistema de justiça criminal paulista: uma análise longitudinal do fluxo da justiça. São Paulo: 2000. (Relatório de Pesquisa).

GARLAND, D. As contradições da "Sociedade Punitiva": o caso britânico. Revista de Sociologia e Politica, Curitiba, n.13, p.59-80, nov. 1999.

. Punishment and Modern Society: a Study In Social Theory. Oxford: Claredon Press, 1990.
GUIMARÃES, A.S.A. Classe, raças e democracia. São Paulo: Editora $34,2002$.

Racismo e Anti-racismo no Brasil. Novos Estudos Cebrap, São Paulo, n.43, p.26-44, nov. 1995.

HACKING, I. How should we do the history of statistics? In: BURCHELL, G.; MILLER, P. (Orgs.). The Foucault Effect: Studies in governmentality. Chicago: The University of Chicago Press, 1991. p.181-196.

LIMA, R.S. de. Criminalidade urbana: conflitos sociais e criminalidade urbana - uma análise dos homicídios cometidos no Município de São Paulo. São Paulo: Sicurezza, 2002.

OLIVEIRA VIANNA, F.J. A evolução da raça. In: DEPARTAMENTO de Estatística do Brasil. Recenseamento do Brasil. Rio de Janeiro: 1920. v.I, segunda parte.

SENRA, N. de C. A coordenação da estatística nacional: o equilíbrio entre o desejável e o possível. Tese (Doutorado) - Universidade Federal do Rio de Janeiro e no Instituto Brasileiro de Informação em Ciência e Tecnologia. Rio de Janeiro, 1998.

Renato Sérgio de Lima: Sociólogo, Chefe da Divisão de Estudos Socioeconômicos da Fundação Seade. 